\title{
Effect of cantala fiber as textile reinforcement on the flexural behaviour of polymer modified mortar
}

\author{
Edy Purwanto ${ }^{1}$, Stefanus Kristiawan ${ }^{1 *}$, Bambang Santosa ${ }^{1}$ and Pungky T Istanto ${ }^{2}$ \\ ${ }^{1}$ SMARTCrete Research Group, Civil Engineering Department, Universitas Sebelas Maret, Surakarta \\ 57126, Indonesia \\ ${ }^{2}$ Civil Engineering Department, Universitas Sebelas Maret, Surakarta 57126, Indonesia
}

\begin{abstract}
Cantala (Agave cantala), plant of the family Asparagaceae and its fibers, belongs to the leaf fibers group. These fibers are made into coarse twines at about $1.2 \mathrm{~mm}$ in diameter. The yarns of the cantala fiber are then interwoven to create textile reinforcements at two meshing size i.e. $5 \times 20 \mathrm{~mm}$ and $10 \times 20 \mathrm{~mm}$. The textiles are used to reinforce polymer modified mortars to improve flexural properties of the mortars. This research aims to investigate the effect of textile reinforcement made from cantala fiber on the flexural behaviour of polymer modified mortar especially its strain hardening response. The parameters to be observed include strength, stiffness, thoughness, ductility and residual strength. The effect of the meshing size of the textile reinforcement on those properties are assesed. In addition, the efficacy of the cantala fiber textile reinforcement to improve the flexural properties of polymer modified mortar is compared with textile reinforcement made from wire mesh. The results indicate that an inclusion of short fibers could alter the post-peak behaviour of the mortar from brittle to ductile failure with softening response. Futher reinforcement of this mortar with cantala fiber textile would turn the softening response to a strain hardening response. The presence of cantala fiber textile reinforcement has minor effect on the flexural strength and stiffness. However, it significantly improve the thoughness, ductility and residual strength of the mortar. Cantala fiber textile reinforcement with a meshing size of $5 \times 20 \mathrm{~mm}$ gives a greater increase on those post-peak properties compared to the the one with a meshing size of $10 \times 20 \mathrm{~mm}$. When comparison is made to the wire mesh, both cantala fiber textile reinforcements show a better properties.
\end{abstract}

\section{Introduction}

Concrete has been utilised in the construction of various infrastructures around the globe. The need of this material remains enormous especially in the developing countries where infrastructures development is put into a national priority to drive the economic activities and growth. The versatility of concrete to meet a variety of design requirements is one of

\footnotetext{
${ }^{*}$ Corresponding author: s.a.kristiawan @ft.uns.ac.id
} 
the prime reasons to choose this construction material. At the same time, concrete technology and inovation are continuously in progress to meet the current and future issues of infrastructures development.

Sustainability is a major issue of today infrastructures development [1]. The issue challenges the concrete industry to create concretes with minimum exploitation to nonrenewable natural resources, less impact to environment, cost-efficient of production, etc. Creation of durable concrete could be a key factor to meet such challenges. Durable concrete promotes a longer service life of the constructed infrastructures with a minimum maintenance throughout their entirely life span. It means durable concrete aiding to reduce the consumption of natural resources for the period of its life span.

It is well known that concrete has a very low tensile strength compared to its compressive strength. Its low tensile strength could be the root of cracking problem even under low imposed load. Cracking may not directly lead to a rupture of the structural concrete but it facilitates the ingress of agggressive agents. The presence of aggressive agents will initiate corrosion of reinforcements which eventually causes a bigger and complicated problems in the future life of the structure. Therefore, concrete industries seek innovative solution by creating concrete which could resist a higher tensile stress. Improvement of tensile properties of concrete has been realised by the development of fiber reinforced concrete (FRC). FRC is characterised by a tensile stress-strain relationship up to failure where this material shows excellent strength, ductility and energy dissipation. Further development of the concrete is the invention of high performance fiber reinforced cement composites (HPFRCC) which do not only exhibit large deformation in tension, but it also provides strain hardening behaviour. The strain hardening behaviour is indicated by the increase of strength after the onset of first cracking while the material exibits large deformation [2-4]. Another cement-based material that has been developed to counter the lack of tensile properties is a textile reinforced composite (TRC). The main difference of this material with FRC or HPFRCC is in the form of fibers inclusion. For FRC or HPFRCC, the fibers are those of short fibers dispersed within the bulk volume of the materials. Meanwhile, for TRC the fibers are woven in the form of textile as a continuos reinforcement of the cement-based material [5].

TRC is a material consisting of two components, namely textile as a reinforcement and concrete (cement-based composite) as a matrix. The type of concrete used in the production of TRC is that of fine-grained aggregate concrete or mortar. Under the increment of tensile loading, matrix will eventually crack at certain level of tensile stress. Once the initiation of cracks occur, all the stresses at the cracks sections are transfered to the textile reinforcement. The post-cracking behaviour of TRC will then be dictated by the strength and the stiffness of the textile reinforcement. High tensile strength of the textile reinforcement will ensure that the reinforcement could carry a higher stress while multiple new cracks are induced in the matrix. The propagation and multiplication of cracks are accountable for the large deformation (ductility) observed at the post-cracking. The propagation of both crack width and crack distribution along the matrix may be controled without compromising the ductility of TRC. This could be achieved by the inclusion of short fibers which are randomly dispersed in the matrix. The short fibers act as crack bridging that minimise the propagation of cracks [6].

Textile reinforcement used in the development of TRC are mostly made of high strength fibers such as basalt, aramid, alkali resistant (AR) glass, carbon (C) and polyparaphenylene-benzo-bisthiazole (PBO). The tensile strength of these fibers are at least 1000 $\mathrm{MPa}$ [7-10]. Meanwhile, medium tensile strengths (400-650 MPa) of nylon yarns have been successfully used to create TRC with strain hardening response. The key to achieve such behaviour lies in the minimum amount of reinforcement ratio to ensure the flexural strength is greater than cracking moment [11]. Other relatively low tensile strengths of materials i.e. 
polyethylene/PE fibers (240 MPa) and wire mesh $(320 \mathrm{MPa})$ have also been used to produce textile reinforcements [12-13]. Off course high tensile strength is beneficial to obtain high strength-high ductility of TRC as compared to those of fibers with low tensile strength. However, in certain circumstances it may costly effective to use the textile reinforcements made from fibers with tensile strength of 200-400 MPa. Tsesarsky et al [8] tested a TRC with textile reinforcement made from PE fibers. Even though the tensile strength of this TRC only attained $7 \mathrm{MPa}$, but the material showed ductile behaviour. This TRC has also been applied to strengthen a beam and it gave an increase of flexural load by $170 \%$. Comparing to the strengthened beam by TRC with textile reinforcement made from AR glass and C fibers, the efficiency of PE was $18 \%$ i.e. higher than $\mathrm{C}(13 \%)$ but lower than AR glass (33\%). Other researchers [12-13] used wire mesh as reinforcement of mortar in a similar manner to that of TRC.

In the authors's point of view, it is necessary to develop cost-efficient TRC for special applications i.e. strengthening low strength and brittle structures such as non-engineered masonry buildings. These buildings particularly exist in developing countries. The materials for manufacturing TRC preferably are available locally. Natural fibers could represent these local resources for the development of TRC. In this current research, natural fibers from the Agave cantala plant are used to manufacture textile reinforcement. The effect of the cantala fiber textile reinforcement on the bending properties of TRC will be investigated. The parameters to be assessed include strength, stiffness, thoughness, ductility and its strain hardening response. The effects of the cantala fiber textile reinforcement on those parameters will be compared with the reinforcement by wire mesh.

\section{Materials and method}

\subsection{Materials}

Textile reinforcements used to reinforced polymer modified mortar were made of natural fibers. The natural fibers, extracted from Agave cantala leaves, were supplied by home industry in Kulon Progo, Yogyakarta, Indonesia. These fibers were made into coarse twines at about $1.2 \mathrm{~mm}$ in diameter. The yarns of the cantala fibers were then interwoven to create textile reinforcements at two meshing sizes i.e. $5 \times 20 \mathrm{~mm}$ and $10 \times 20 \mathrm{~mm}$ (see Figure 1). The average tensile strength of the yarns was $150 \mathrm{MPa}$. The textiles were treated by mean of coating applied on the surface of the yarns using unsaturated polyester resin (UPR). In this way, the fibers were protected from the alkalinity of the mortar. For comparison purpose, a wire mesh having size of $11.2 \times 22.4 \mathrm{~mm}$ was also used as reinforcement. The diameter of the wire was $0.8 \mathrm{~mm}$ with a tensile strength of $314 \mathrm{MPa}$.

The textiles were then used to reinforce polymer modified mortars to improve flexural properties of the mortars. The ingredients for making the mortars were cement $(\mathrm{C})$, fine grained sand (S), water (W), polyvinyl acetate (PVA), accelerator (Ac) and superplasticizer $(\mathrm{Sp})$. The $\mathrm{S}$ were selected in such they passed through a meshing size of $1.18 \mathrm{~mm}$ but retained on a meshing size of $0.5 \mathrm{~mm}$. The proportion of the mortars is given in Table 1 . The amount of $\mathrm{W}$ shown in the table is a total water consisting of free water and water contained in PVA, Ac and Sp.

Five type of thin beam specimens having size of 10x50x250 mm were made in this research. The first was a mortar specimen $(\mathrm{N})$ with a composition as given in Table 1 . The second specimen was a mortar with similar composition of $\mathrm{N}$ but with an addition of short cantala fibers (SF) at about $0.45 \%$ by weight of mortar. These fibers were added during mixing. The third to fifth specimen were mortars with similar composition of SF but reinforced with three different textiles i.e. cantala fiber textile reinforcement with a 
meshing size of $5 \times 20 \mathrm{~mm} \mathrm{TR}(0.5 \times 2)$, cantala fiber textile reinforcement with a mesihing size of $10 \times 20 \mathrm{~mm}$ TR $(1 \times 2)$ and wire mesh (WM) with a meshing size of $11.2 \times 22.4 \mathrm{~mm}$. The specimen was prepared as follows: a half layer of mortar $(2.5 \mathrm{~mm}$ thickness $)$ was laid on the wooden mould and then textile reinforcement was placed to rest on top of this layer. The final layer of mortar was laid to cover the textile reinforcement. The top layer of the mortar was pressed manually to aid in eliminating air within the mortar. Each type of specimens was represented by 5 beams for flexural testing.

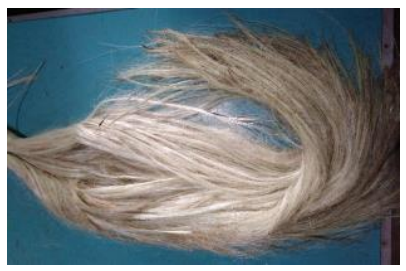

(a)

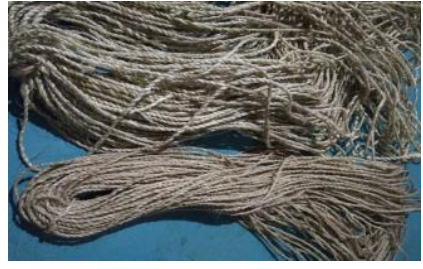

(b)

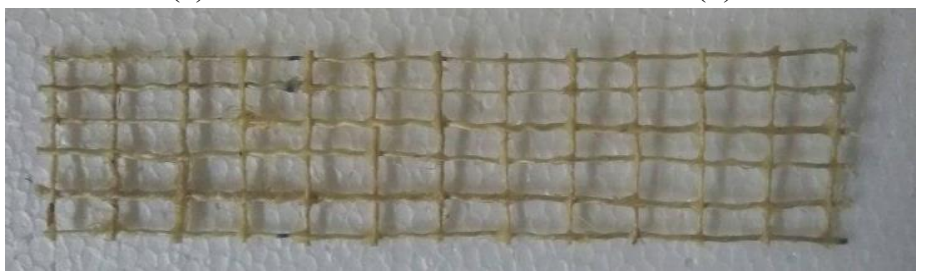

(c)

Fig. 1. Original cantala fibers (a), the yarns (b) and textile reinforcement (c)

Table 1. Proportion of mortars

\begin{tabular}{|c|c|c|c|c|c|c|c|}
\hline Spec. ID & $\begin{array}{c}\mathrm{C} \\
(\mathrm{kg})\end{array}$ & $\begin{array}{c}\mathrm{S} \\
(\mathrm{kg})\end{array}$ & $\begin{array}{c}\text { W } \\
(\mathbf{k g})\end{array}$ & $\begin{array}{c}\text { PVA } \\
\text { (kg) }\end{array}$ & $\begin{array}{c}\text { Ac } \\
(\mathbf{k g})\end{array}$ & $\begin{array}{c}\text { Sp } \\
(\mathbf{k g})\end{array}$ & $\begin{array}{l}\text { fiber } \\
\text { (\%)* }\end{array}$ \\
\hline $\mathrm{N}$ & 1 & 2 & 0.35 & 0.2 & 0.083 & 0.01 & - \\
\hline SF & 1 & 2 & 0.35 & 0.2 & 0.083 & 0.01 & 0.45 \\
\hline $\begin{array}{c}\text { TR(1 }(1 \times 2), \\
\text { TR(0.5x2), } \\
\text { WM }\end{array}$ & \multicolumn{7}{|c|}{$\begin{array}{l}\text { Similar composition to SF but the mortars are reinforced with } \mathrm{TR}(1 \times 2), \mathrm{TR}(0.5 \times 2) \text { anc } \\
\text { WM, respectively. }\end{array}$} \\
\hline
\end{tabular}

* by weight of mortar

\subsection{Method}

Flexural testing was carried out on specimens after 28 days of age using Universal Testing Machine (UTM) by mean of third point loading. The span length (support to support) was determined at $210 \mathrm{~mm}$. The load was applied at a displacement rate of $5 \mathrm{~mm} / \mathrm{min}$. The load and the corresponding deflection up to failure were recorded automatically by the machine.

\section{Results and discussion}

\subsection{Load-deflection behaviour}

Figure 2 shows the load-deflection behaviour up to failure for all types of specimens. The average values are presented in Figure 2.(f). It is interesting to note that at the pre-peak load, all specimens show a similar behaviour i.e. very steep straight curves are observed at the beginning of loading and then at some points between 40-70 $\mathrm{N}$ of loading, the curves 
are shifted slightly to the right indicating an initiation of microcracks have occurred on the specimens. After microcracks arise, the specimens could maintain their proportional loaddeflection behaviour with a little lower of stiffness.

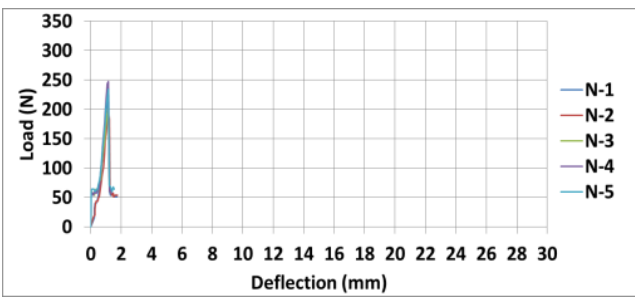

(a)

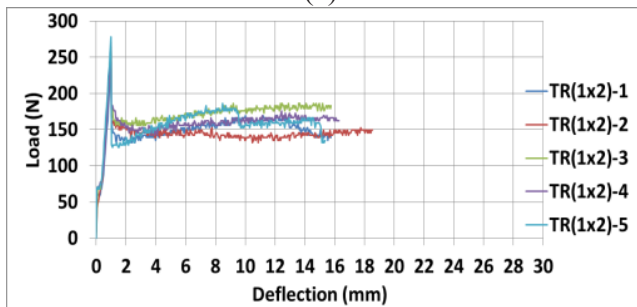

(c)

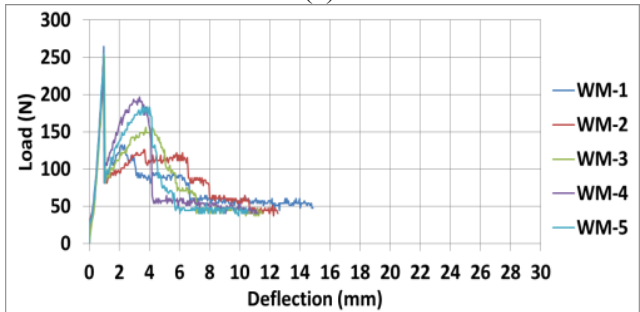

(e)

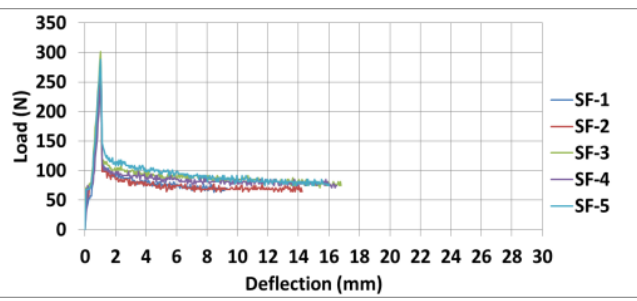

(b)

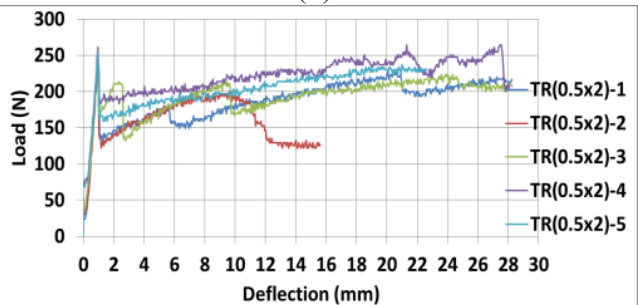

(d)

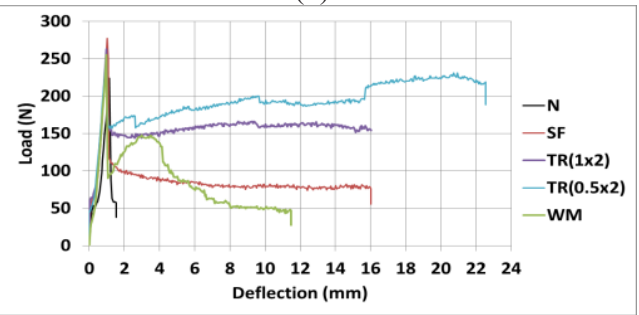

(f)

Fig. 2. Load-deflection behaviour of various specimens under flexural loading

Obvious differences are observed at the post-peak load. For normal mortar $(\mathrm{N})$, sudden drop of peak-load leading to failure is observed. This behaviour is typical of brittle material. Inclusion of short fibers in the mortar (SF) significantly transforms from brittle failure to ductile failure. After peak-load drops, a large deformation is observed in SF. A softening response is noted in this material. When the textile reinforcements are used to reinforced the SF mortar, the softening response turns to a strain hardening response. Each type of textile reinforcement provides a unique strain hardening response. For TR $(1 \times 2)$ the hardening level is small even though it gives an increase of residual load more than $200 \%$ to that of SF. For TR $(0.5 \times 2)$ the hardening behaviour causes the residual stress approaching the peak-load level. For reinforcement using wire mesh (WM), the strain hardening attain an ultimate value at short deformation level (about 2-3 times of deformation at the first peak-load). After this ultimate value (second peak-load), the material shows softening response.

\subsection{Key parameters}

This section discusses the key parameters deduced from the load-deflection curves given in Figure 2. The parameters to be examined include ultimate stength, stiffness, toughness, ductility and residual strength with a particular interest to assess the influence of textile reinforcements. These key parameters and their average values are tabulated in Table 2. It 
is clear that the ultimate strength of the mortar is only slightly affected by cantala fibers both in the form of short fibers and textile reinforcements. Inclusion of cantala short fibers (SF) give an increase of strength at $11.5 \%$. Additional increase of ultimate strength could not be expected when textile reinforcement is introduced. The influence of textile reinforcement on strength is minor compared to its influence on the deformation. The explanation is as follows. Under flexural loading, the mortar specimens undergo tension and compression stresses. Since the property of plain mortar in tension is inferior compared to that in compression, the flexural strength of mortar is controlled by its tension capacity. Inclusion of fibers is expected to improved its tension property with a consequence of increasing flexural strength. The effectivity of the fibers to improve the flexural strength depends on the action zone of the fibers. For thin prism specimen with textile reinforcement sets at the middle section, the textile reinforcement will not effective to improve the flexural strength. However, the induced stresses will be transferred to the textile reinforcement once the mortar develop sufficient macrocracks. These macrocracks occur at peak-load after which causing the sudden drop of the load and activating the tensile action of textile reinforcement. Hence, the influence of textile reinforcement could significantly only be observed at post-peak load especially on the capability of the mortar to undergo large deformation and strain hardening.

The flexural stiffness is a parameter to describe how material will undergo deflection as it is loaded in flexure. The flexural stiffness of the mortars investigated in this study could be identified from the load-deflection relationship curves up to peak load. From Figure 2, it may be reasonably assumed to define the stiffness index as the ratio of the peak-load to its respected deflection. The results show that an addition of cantala short fibers could improve the stiffness index of mortar by $19.44 \%$. If mortar containing short fibers is reinforced with cantala fibers textile reinforcements or wire mesh, the stiffness index is expected to increase futher by no more than $15 \%$. The increase may be attributed to the ability of the fibers and textile reinforcements to some extent restrain the propagation of microcracks.

Table 2. Key paramaters values

\begin{tabular}{|c|c|c|c|c|c|}
\hline Specimen & $\begin{array}{c}\text { Strength } \\
\text { (N) or (MPa) }\end{array}$ & $\begin{array}{c}\text { Stiffness } \\
\text { Index }\end{array}$ & $\begin{array}{c}\text { Toughness } \\
\text { Index }\end{array}$ & $\begin{array}{c}\text { Ductility } \\
\text { Index }\end{array}$ & $\begin{array}{c}\text { Residual } \\
\text { Strength (N) }\end{array}$ \\
\hline N & $223.78(9.34)$ & 195.95 & 14.03 & 1.29 & 57.48 \\
\hline SF & $249.65(10.49)$ & 234.20 & 138.79 & 11.26 & 75.48 \\
\hline TR(1x2) & $263.09(11.05)$ & 269.23 & 253.60 & 20.83 & 154.19 \\
\hline TR(0.5x2) & $252.31(10.60)$ & 264.50 & 435.78 & 36.11 & 216.96 \\
\hline WM & $255.06(10.71)$ & 269.94 & 99.07 & 9.55 & 47.22 \\
\hline
\end{tabular}

Note: The stiffness, toughness and ductility index represent relative values. Therefore, no unit is indicated.

Figure 2 suggests that inclusion of cantala short fibers drastically change the deformation of the mortar; from brittle behaviour to ductile behaviour. Further changes in the behaviour are observed when the mortars are reinforced with textile. The changes in the deformation behaviour are best characterised by the toughness and ductility index. The toughness is indicated by the area under the load-deflection curve. This area characterises the capability of the material to absorp energy after peak-load. Meanwhile, the ductility is defined by the ratio of deformation at failure to that at peak-load. This parameter also indicates the capability of material to deform after peak-load before rupture. The ductility could also be quantified by the ratio of toughness at failure to that at peak-load. The latter is adopted in this research. The experimental results show that the toughness index of SF is 138.79. When this mortar is reinforced with $\mathrm{TR}(1 \times 2), \mathrm{TR}(0.5 \times 2)$ and $\mathrm{WM}$, the toughness index is increased by $83 \%, 214 \%$ and $-71 \%$, respectively. An enlargement of the ductility 
index at about $85 \%, 221 \%$ and $-73 \%$ could be expected for reinforcement of SF mortar with $\mathrm{TR}(1 \times 2), \mathrm{TR}(0.5 \times 2)$ and $\mathrm{WM}$, respectively. The increase in the toughness and ductility of SF mortar due to cantala textile reinforcements could be traced from the tensile action of these reinforcements after peak-load. As previouly stated, the stresses transfer to the textile reinforcements could only occur after sufficient macrocracks develop in the mortar. These cracks cause a drop of peak-load and activate the action of textile reinforcements in the post-peak load. The textile reinforcements are accountable for the capability of mortar to undergo large deformation and strain hardening. $\mathrm{TR}(0.5 \times 2)$ has a reinforcement ratio twice than that of $\operatorname{TR}(1 \times 2)$. Consequently, the toughness and ductility index of $\operatorname{TR}(0.5 \times 2)$ much greater than that of $\operatorname{TR}(1 \times 2)$. For reinforcement with wire mesh $(\mathrm{WM})$, it is indicated that wire mesh could also turn the mortar from showing a softening response to strain hardening response. However, the material rupture at a lower deformation than that of SF. Hence, the toughness and ductility index of WM is lower than the coressponding SF.

The residual strength of the SF at the end of softening response equals to $75.48 \mathrm{~N}$. The textile reinforcements enhance the residual strength due to the strain hardening response. The highest residual strength is observed on TR $(0.5 \times 2)$ i.e. $217 \mathrm{~N}$. This should be expected since this material have the highest reinforcement ratio. For mortar reinforced with wire mesh, initially the material shows strain hardening response and then follows by softening response. That is why the residual strength of this material (WM) is only $47.22 \mathrm{~N}$ i.e. even lower than the SF.

\section{Conclusions}

This research investigates the influence of cantala fiber textile reinforcement on the flexural characteristics of polymer modified mortar and the main findings are as follow:

- Inclusion of short fibers could alter the post-peak behaviour of the mortar from brittle to ductile failure with softening response. Futher reinforcement of this mortar with cantala fiber textile would turn the softening response to a strain hardening response.

- The strain hardening response of the cantala textile reinforced mortar is influenced by the reinforcement ratio. A higher reinforcement ratio of $\operatorname{TR}(0.5 \times 2)$ shows a higher strain hardening response than a lower reinforcement ratio of $\mathrm{TR}(1 \times 2)$.

- The strain hardening response of cantala fiber textile reinforcements is different to that of reinforcement using wire mesh (WM). For cantala fiber textile reinforcement the strain hardening is continuous up to failure while for WM the strain hardening is followed by a softening response.

- The reinforcements of the mortars with cantala textile or wire mesh have a minor effect on the flexural strength and stiffness but they signiificantly affect the toughness, ductility and residual strength of the mortars.

This research is financially supported by the University of Sebelas Maret through Maintenance Research Group for the year of 2017.

\section{References}

1. K.J.G. Ong, Proc. Eng 171, 14-21 (2017)

2. S. Gwon, M. Shin, J. ACF 2(1), 67-80 (2016)

3. T. Simoes, H. Costa, D. Dias-da-Costa, E. Julio, Constr. Build. Mat. 137, 548-556 (2017)

4. M Singh, A.H. Sheikh, M. S. M. Ali, P. Visintin, M. C. Griffith, Constr. Build. Mat. 138, $12-25$ (2017) 
5. M. Mobasher, Mechanics of fiber and textile reinforced cement composites, CRC Press, Florida (2012)

6. R. Barhum, V. Mechtcherine, Eng. Frac. Mech. 92, 56-71 (2012)

7. P. Larrinaga, C. Chastre, H. C. Biscaia, J. T. San-Jose, Mat. Des. 55, 66-74 (2014)

8. M. Tsesarsky, A. Peled, A. Katz, I. Anteby, Constr. Build. Mat. 44, 514-523 (2013)

9. L. Ombres, Comp. Struct. 94, 143-155 (2011)

10. R. Contamine, A. Junes, A. S. Larbi, Constr. Build. Mat. 51, 405-413 (2014)

11. M. Zargaran, N. K. Attari, S. Alizadeh, P. Teymouri, Constr. Build. Mat. 137, 459-469 (2017)

12. A. M. El-kholy, H. A. Dahish, Ains Shams Eng. J. 7(2), 717-728 (2016)

13. H. Zhao, M. N. S. Hadi, Proc. Eng. 14, 2848-2855 (2011) 